This item was submitted to Loughborough's Research Repository by the author.

Items in Figshare are protected by copyright, with all rights reserved, unless otherwise indicated.

\title{
Is simulation in health different?
}

PLEASE CITE THE PUBLISHED VERSION

http://dx.doi.org/10.1057/jors.2014.25

PUBLISHER

(c) Palgrave Macmillan

VERSION

AM (Accepted Manuscript)

LICENCE

CC BY-NC-ND 4.0

REPOSITORY RECORD

Tako, Antuela A., and Stewart Robinson. 2019. "Is Simulation in Health Different?". figshare. https://hdl.handle.net/2134/14455. 
This item was submitted to Loughborough's Institutional Repository (https://dspace.lboro.ac.uk/) by the author and is made available under the following Creative Commons Licence conditions.

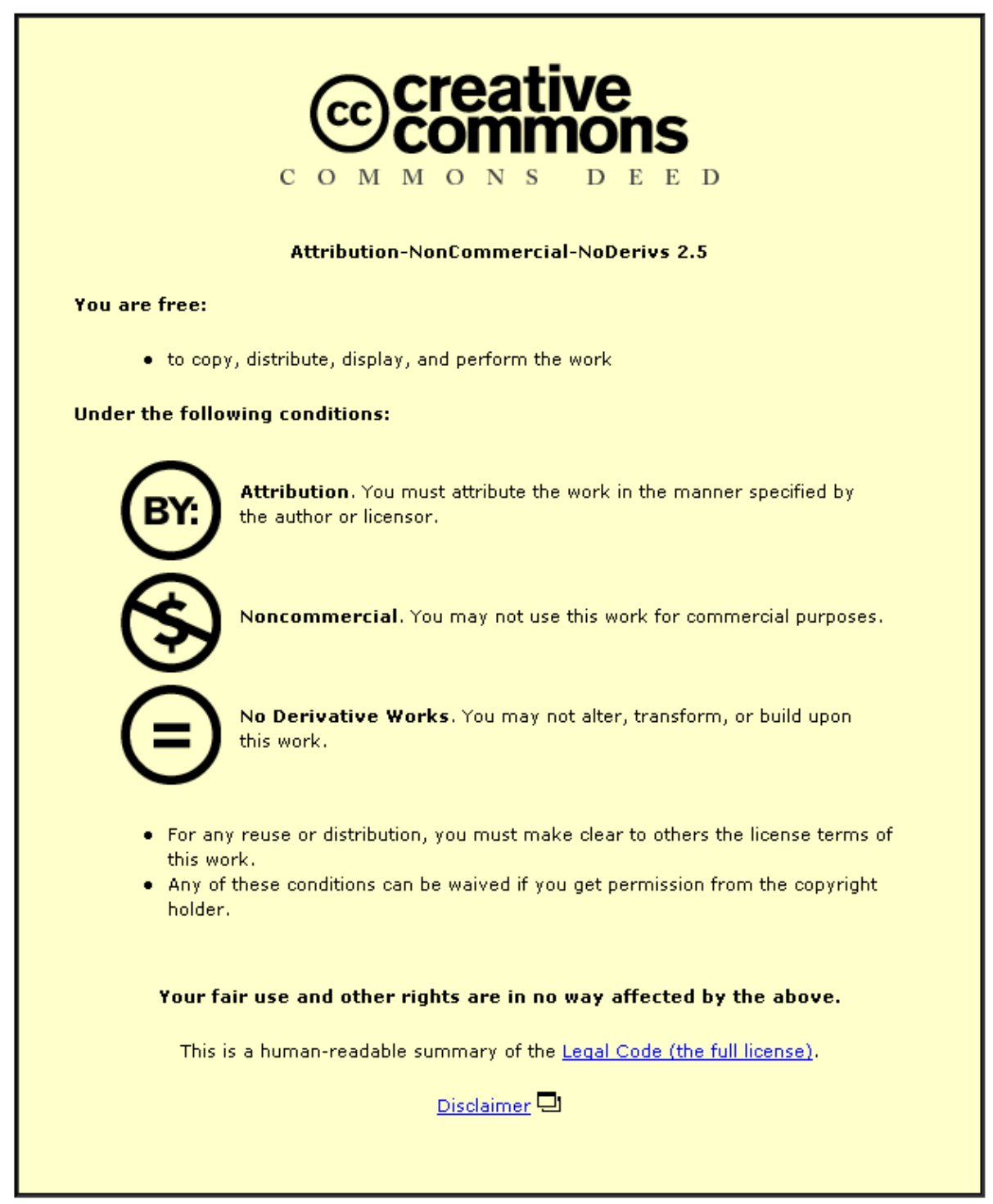

For the full text of this licence, please go to: http://creativecommons.org/licenses/by-nc-nd/2.5/ 


\title{
IS SIMULATION IN HEALTH DIFFERENT?
}

\author{
Antuela A Tako and Stewart Robinson \\ Management Science and Operations Management Group \\ School of Business and Economics \\ Loughborough University \\ Loughborough, LE11 3TU \\ UNITED KINGDOM \\ a.takou@lboro.ac.uk,s.l.robinson@lboro.ac.uk
}

\begin{abstract}
It is often stated that health simulation is quite different and even that it is more difficult than in other sectors. But- is simulation in health really different to simulation in other sectorselsewhere? In this paper we explore this question through a survey of simulation modellers and academics. We elicit their opinions across a range of factors concerning the difficulties of health modelling against modelling in other domains. The analysis considers the responses of the whole group of respondents and the sub-group of respondents who have experience both in and outside of health modelling. The results show that, overall, there is a perception that health modelling is different and that it is more difficult across a range of factors. The implications for simulation research and practice in health are discussed.
\end{abstract}

Keywords: Health Modelling, Simulation 


\section{IS SIMULATION IN HEALTH DIFFERENT?}

\section{INTRODUCTION}

It is often stated that the application of simulation in health is different and even that it is more difficult than in other sectors. This is posited as one of the reasons why simulation has been less successful in health when compared to other sectors such as manufacturing and military applications (Brailsford et al, 2009; Naseer et al, 2009; Jahangirian et al, 2012). The difficulty for health modelling arises from factors such as complexity, multiple decision makers and busy stakeholders, which all pose particular challenges to simulation modelling in health (Harper and Pitt, 2004; Kuljis et al, 2007; Eldabi, 2009; Brailsford et al, 2009; Brailsford et al, 2013). However, there does not appear to be any empirical evidence to backup such a claim. Indeed, there is a danger of modellers from one application area making judgements about the relative ease or difficulty of their modelling task as compared to modelling in other sectors when they have only limited experience outside their immediate domain of interest. It may be that simulation modellers in any sector - be it health, manufacturing, military, services etc. - consider their modelling task to be very different, and possibly more difficult, than for any other sector.

In this paper we explore the question of whether health modelling is different and whether it is more difficult. A survey is carried out of simulation modellers' perceptions about the differences between modelling in health and other sectors. We start by providing a brief summary of the key differences proposed in the literature. Then we describe the questionnaire, how the survey was performed and the nature of the respondents' background. The results of the survey are reported, first for all respondents to the questionnaire and then for a subset who have experience both in and outside of health modelling. We also perform a brief analysis to see whether there are any differences in the responses from those working in different countries, and so different health systems. We conclude by discussing the findings, the limitations of the study and the implications of the work for simulation research and practice. The contribution of this work is to provide an empirical basis for identifying and understanding the differences in health modelling. 
For the purposes of clarity, in this paper the term 'simulation' refers to its use in operational research. This involves computer based simulations which are used to aid understanding and decision-making. Given the population surveyed this will primarily involve discrete-event simulation, but also possibly system dynamics and agent-based simulation.

\section{THE CHALLENGES OF SIMULATION IN HEALTH}

There is much discussion on the use and potential use of simulation in health with applications ranging across planning, scheduling, reorganisation and management of healthcare and hospital services, communicable diseases, bio-terrorism, screening, costs of illness, economic evaluation (comparing alternative healthcare interventions), policy and strategy evaluation, and performance modelling (Fone et al, 2003; Mustafee et al, 2010; Günal and Pidd, 2010). Comprehensive reviews of the use of simulation in health are provided by Jun et al (1999), Tunnicliffe Wilson (1981), Fone et al (2003), Jacobson et al (2006), Sobolev et al (2011) and van Lent et al (2012).

A range of authors specifically focus on the challenges and differences of simulation and modelling in health. Brailsford et al (2009) suggest that simulation is an established part of the decision-making process in both manufacturing and the military, while in health there is no such widespread adoption of simulation. They see a key issue being that it is very difficult to identify the stakeholders in a health environment. This relates to where the boundary of the problem being investigated lies, the accessibility of stakeholders, the differing time-scales to which health professionals and academics (modellers) work, and research ethics.

Eldabi (2009) also identifies stakeholder issues as a barrier to the implementation of simulation in health. In particular, he discusses the conflicting interests of the stakeholders leading to a set of conflicting goals. He also identifies issues emerging from a lack of relevant tools; most simulation software was originally developed for manufacturing applications. Again, the problem of a mismatch between the expectations of the modellers and the stakeholders is identified as problematic.

Young et al (2009) highlight three challenges for health modelling: developing models of appropriate detail, understanding how modelling is linked to decision-making, and dealing with the cultural barriers to modelling in the health sector. Meanwhile, Kuljis et al (2007) 
discuss seven axes of differentiation that set health modelling apart: patient fear of death, medical practitioners, healthcare support staff, healthcare managers, political influence and control, society's view, and utopia.

In their report on simulation for strategic planning in healthcare, Pitt (2008) identify many of the challenges listed above. In addition they point to the heterogeneity of healthcare organisations and the constantly changing environment. This makes the development of generic models particularly challenging. Indeed, Günal and Pidd (2010) point out that many simulation studies reported in the literature are unit or facility specific and are never re-used. Meanwhile, Fackler and Spaeder (2011) speaking from the point of view of clinicians identify two key issues: poor understanding of mathematics among clinicians, and modellers have not yet chosen the right strategy or domain for their work. Over 30 years ago, Tunnicliffe Wilson (1981) similarly identified the difficulties doctors might face in interpreting management statistics.

In summary, the literature discussed above highlights some opinions, largely expressed by academics specialising in health, about the differences and-challenges that differentiatefor simulation in health from its use in other domains. There does not appear to be any empirical evidence to back-up these claims. Also, Ffor all that we know, modellers in other domains could be facing difficulties of a similar nature. Kirchhof and Meseth (2012) make some attempt to address this lack of empirical evidence by surveying 121 German hospitals, although they only received responses from 32. Their focus is on the reason for low adoption of simulation in healthcare. Among those that responded the key reasons for low adoption are identified as cost, lack of simulation skills and low levels of awareness of simulation's benefits. Kirchhof and Meseth, however, do not attempt to determine the differences between health modelling and modelling in other domains. It is to this question that we turn our attention. Our motivation for this research is to test the opinions expressed in the literature about the challenges of differences in -health modelling by utilising a survey questionnaire to understand the views of those with experience of both health modelling and modelling in other sectors. 


\section{THE SURVEY}

\subsection{Development of the Questionnaire}

The questionnaire used for the survey was developed based on a review of the literature on the differences and challenges of modelling in health. What emerged was a range of factors that might differentiate health modelling which we classified under four headings as follows:

- The Problem Perspective: evident structure of problems, complexity of systems, rate at which the nature of the problem changes, messiness of the problems

- The Cost and Data Perspective: effort required to collect the data, difficulty in accessing data, problems created through ethical issues, ease of results interpretation

- External Factors Perspective: influence of political events, rate at which results become obsolete, appropriateness of simulation software

- Organisational Factors Perspective: incentive to initiate change, resistance to change, acceptance of study results, ease of developing generic models, clients lack of time, implementation difficulties due to busyness of clients, ease of identifying stakeholders

To illustrate how these factors were derived we provide three examples: complexity of systems, difficulty in accessing data and appropriateness of simulation software. The complexity of systems in health is discussed by a number of authors. Lowery et al (1994) point out that healthcare systems are more complex than industrial systems mainly due to the human factors involved (e.g. patients, physicians, nurses) whose interactions do not result in the simple production of a final product, 'health'. Harper and Pitt (2004) and Brailsford et al (2009) discuss the complexity that arises from the interconnectivity of healthcare systems and Young et al (2009) point to the scale of healthcare systems as a source of complexity. Complexity also arises from uncertainty over the needs of patients (Fone et al, 2003) and from the need to address multiple, competing objectives (Harper and Shahani, 2002).

Access to data is problematic for a number of reasons. Reams of data may be available, but they may not be in a form suitable for modelling (Eldabi, 2009; Lane et al, 2003). Brailsford (2005) discusses the messiness of data and the need to spend time and money on data cleaning and analysis to get the information in the right form. Harper and Pitt (2004) identify the problem of data quality and availability. Data are often unavailable or too detailed in the 
form of individual patient records, and they are rarely used to inform future planning. They also refer to their experience of dealing with data prone to errors.

Some see an issue with the appropriateness of simulation software, not least because many simulation tools have been developed initially for application in the manufacturing domain. Eldabi (2009) refers to the Research into Global Healthcare Tools (RIGHT) project (wwwedc.eng.cam.ac.uk/right accessed February 2014June 2013) in which it was found that there is a lack of readily available tools for healthcare modelling. That said, a number of simulation software providers have created tools specifically for healthcare, for instance, Scenario Generator (www.scenario-generator.com accessed February 2014), FlexSim Healthcare (www.flexsim.com/flexsim-healthcare accessed February 2014) and MedModel (www.promodel.com/products/medmodel accessed February 2014).

The questionnaire provided a statement about each of the above factors (e.g. 'in health there is less evident structure') and asked for a response according to a four-point Likert scale ('strongly agree', 'agree', 'disagree' and 'strongly disagree'), with a fifth 'not sure' option. As such, we were asking respondents to state whether they perceived health modelling to be more difficult or not. An 'or not' response ('disagree' or 'strongly disagree') would mean that they either perceived that no difference exists, or that modelling in other sectors for that factor is more difficult. Meanwhile, a 'not sure' response meant that they felt unable to comment, perhaps because they had limited experience of encountering that factor in health and in other sectors.

We recognise from the outset that the survey was measuring perceptions of the relative difficulties of health modelling. This in itself is almost certainly subject to bias based on the respondents' experience in performing simulation studies in different sectors. As such, the results provide a subjective measure of the differences, based on perceptions, rather than an objective measure. We shall return to this issue in the conclusion of the paper.

At the end of the questionnaire the respondents were asked to state their overall opinion regarding the statement that simulation in health is different to other sectors. As for the other statements, they rated their response according to a four-point Likert scale with the fifth option to respond with 'not sure'. 
Prior to sending the questionnaire out, it was tested with two colleagues who provided useful feedback on how to improve the questionnaire. A pilot survey was also run with 14 randomly chosen attendees at the 2010 Winter Simulation Conference in Baltimore, Maryland. The preliminary results were analysed and some slight changes were made. The questionnaire was set-up on-line using the Bristol Online Survey (survey.bris.ac.uk accessed June Z013February 2014).

\subsection{Administration of the Survey}

A request to complete the survey was sent to all authors of papers at the 2010 Winter Simulation Conference in Baltimore, Maryland. The data on conference paper authors is publically available from the proceedings which are held online at informs-sim.org (accessed June 2013February 2014), but it does take time to manually extract their email addresses. The list of authors does not cover all attendees at the conference and not all authors will necessarily have attended the conference, with some deferring the presentation of their paper to their co-authors.

An email was sent to all 444 conference authors; around 30 were returned as undeliverable. The email outlined the background to the survey and pointed the recipients to the web address for the questionnaire. To incentivise responses, all respondents who identified themselves were entered into a prize draw. The first prize was an Amazon Kindle and the two runners-up prizes were a copy of a book on conceptual modelling for simulation (Robinson et al, 2010).

\subsection{The Survey Respondents}

In total 121 responses were received, giving a response rate of about 29\%, of which 113 were usable. Table 1 provides basic demographic data for the respondents according to the first three questions in the questionnaire. These show the simulation modelling experience of the respondents, the split of their modelling activity (research, teaching, consulting, other), and the split of their modelling work in different sectors (health, manufacturing, government, services, other). For the latter two, each respondent was asked to state the percentage split of their modelling work between the different activities and sectors. The results in Table 1 summarise the average of those percentages. 
Table 1 Demographic Data for the Survey Respondents

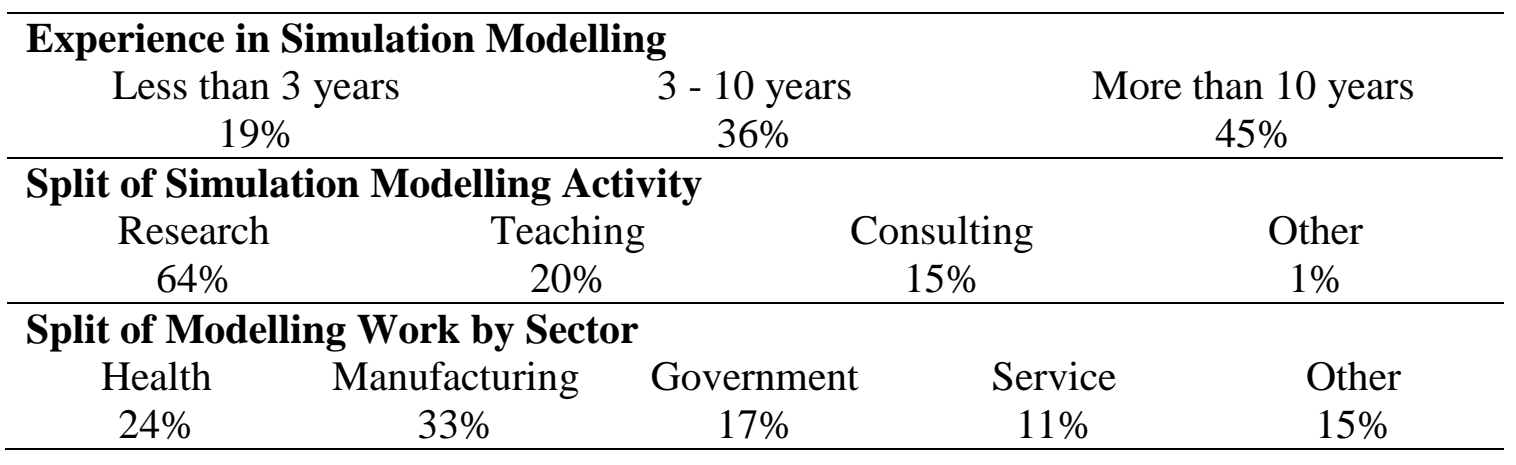

The respondents generally have a high level of experience with $45 \%$ having spent more than 10 years working in simulation. As would be expected from authors at a primarily academic conference, the respondents spend most of their time in research activities and only $15 \%$ of their time on average in consulting work. However, given the applied nature of much simulation research and the papers at the Winter Simulation Conference, it is likely that a higher proportion of the respondents' time is spent working on real problems through research. The highest proportion of the respondents' time involves working in the manufacturing sector, with health coming in second at $24 \%$. The percentage of work in health is surprisingly high, but probably reflects a higher interest in the survey from those working on health related problems.

\section{SURVEY RESULTS: OVERALL ANALYSIS}

We now present the results from the survey based on the factors under the four perspectives outlined in section 3. We also report the results of the overall opinions about whether health modelling is different to other sectors. In the next section we will focus on how the results vary depending on the respondents’ experience with health modelling.

\subsection{The Problem Perspective}

The four statements on the problem perspective aimed at gauging respondents' opinions about the difference in the nature of problems modelled in health compared to other domains. The bar charts in Figure 1 show respondents' opinions on a 4-point Likert scale and a 'not sure’ option, for the four separate statements included under the problem perspective. 
A close observation of the bar charts (Figure 1) reveals that on the whole there are proportionally more responses in agreement with the statements on the less evident structure, more complex systems and messier problems (including both strongly agree and agree positions), compared to disagreement positions (including both disagree and strongly disagree). This suggests that there is a tendency in respondents' opinions to agree that modelling in health is more difficult in relation to these factors. On the contrary, respondents' opinions on the statement that problems change more, are reasonably equally divided between agree and disagree positions. In this paper we are mainly interested in identifying whether there is a difference between the agree and disagree positions for these statements. Hence, to confirm these observations, we use the binomial test (Sheskin, 2007), where we compare the proportion of respondents' opinions between the amalgamated agree and disagree categories. We test against the null hypothesis that there is no difference in the level of difficulty between modelling in health and other sectors. At a 5\% level of significance, the test confirms these observations (Table 2), hence concluding that respondents tend to support the view that modelling in health is more difficult due to the less evident structure, more complex systems and messier problems, but respondents' views were almost equally divided on the statement that problems change more in health than in other sectors.

Figure 1 Frequencies of respondents' opinions about the difference between modelling in health and other domains with respect to the nature of problems

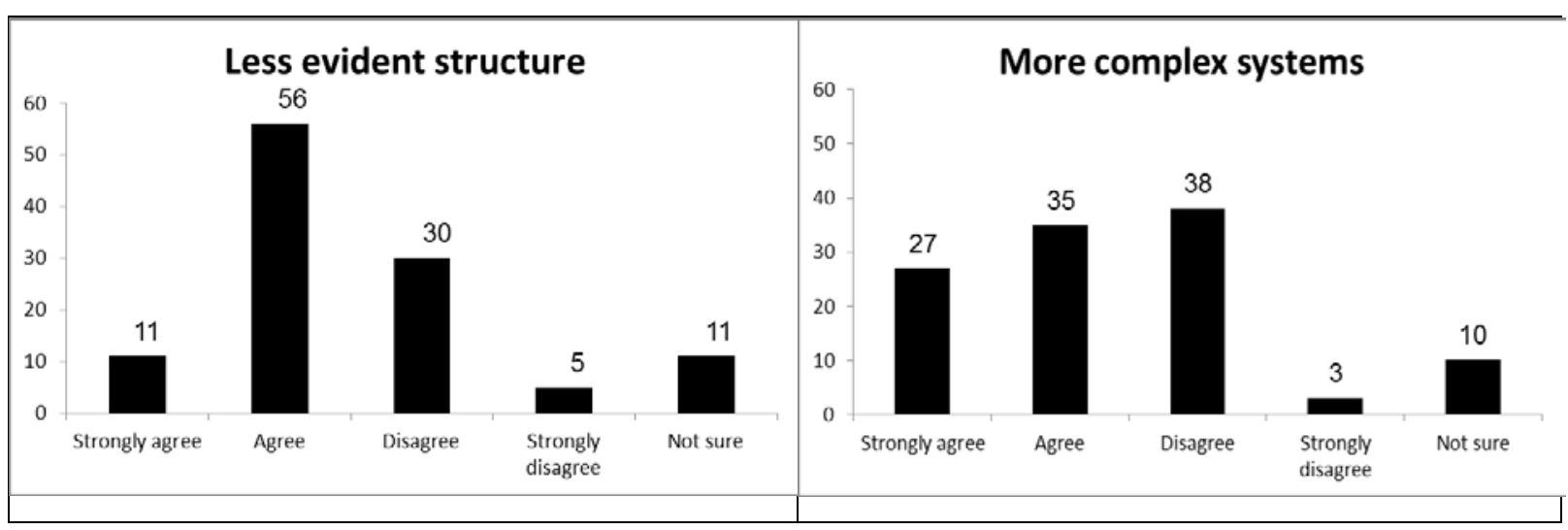




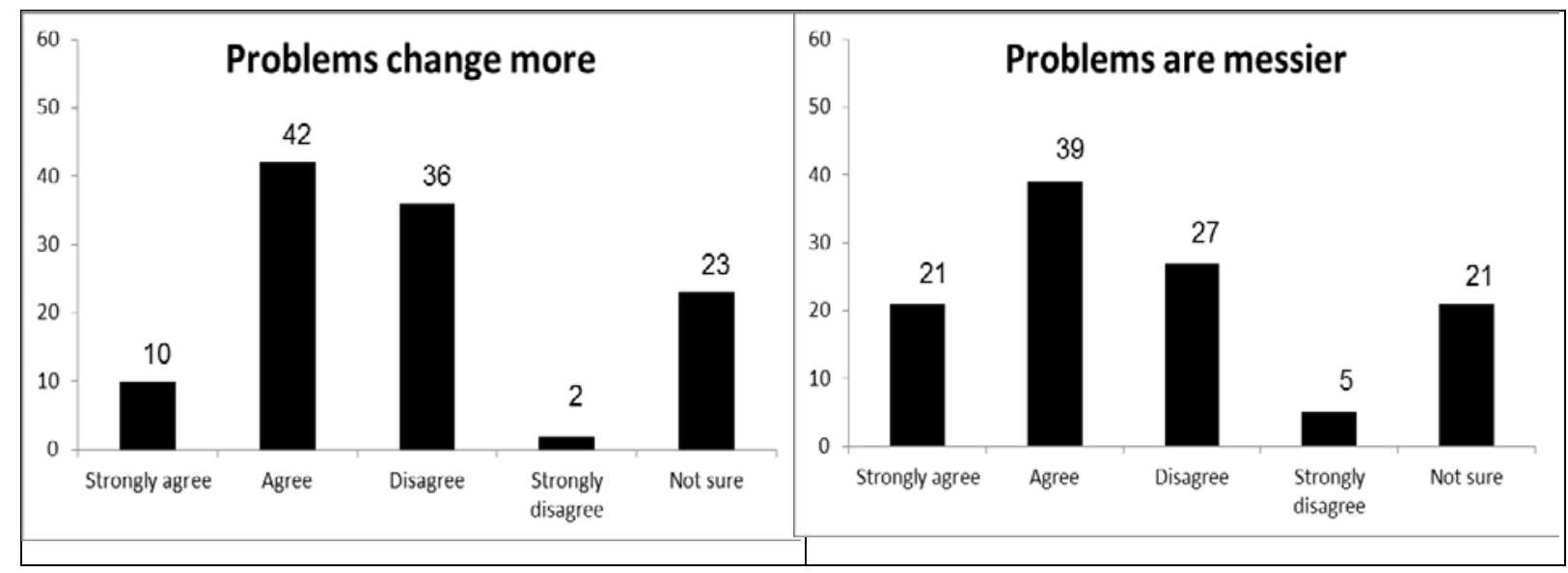

Table 2 Proportion of grouped agree and disagree opinions on the nature of problems and the results of the Binomial test comparing the two groups against the $H_{0}$ : there is no difference in the level of difficulty between modelling in health and in other sectors

\begin{tabular}{lcccl}
\hline \multicolumn{1}{c}{ Statement } & Agree & Disagree & $\begin{array}{c}\text { Binomial test } \\
(p \text {-value })\end{array}$ & $\begin{array}{c}\text { Conclusion: Is health } \\
\text { modelling more difficult? }\end{array}$ \\
\hline Less evident structure & $66 \%$ & $34 \%$ & 0.02 & Yes (Reject $\left.\mathrm{H}_{0}\right)$ \\
More complex systems & $60 \%$ & $40 \%$ & 0.049 & Yes (Reject $\left.\mathrm{H}_{0}\right)$ \\
Problems change more & $58 \%$ & $42 \%$ & 0.171 & No (Do not reject $\left.\mathrm{H}_{0}\right)$ \\
Problems are messier & $65 \%$ & $35 \%$ & 0.005 & Yes (Reject $\left.\mathrm{H}_{0}\right)$ \\
\hline
\end{tabular}

\subsection{The Cost and Data Perspective}

The four statements included in this question aim to identify respondents' opinions about the differences in the difficulties faced in health and other sectors in terms of cost and data requirements involved. For each statement the number of responses on the 4-point Likert scale and a 'not sure' option is presented in Figure 2. The majority of respondents agree or strongly agree with the first three statements that issues related to data collection, data access and research ethics make modelling in health more difficult. A different view is taken by respondents with respect to difficulties encountered with the interpretation of model results.

Figure 2 Frequencies of respondents' opinions about the difference between modelling in health and other domains with respect to data issues 


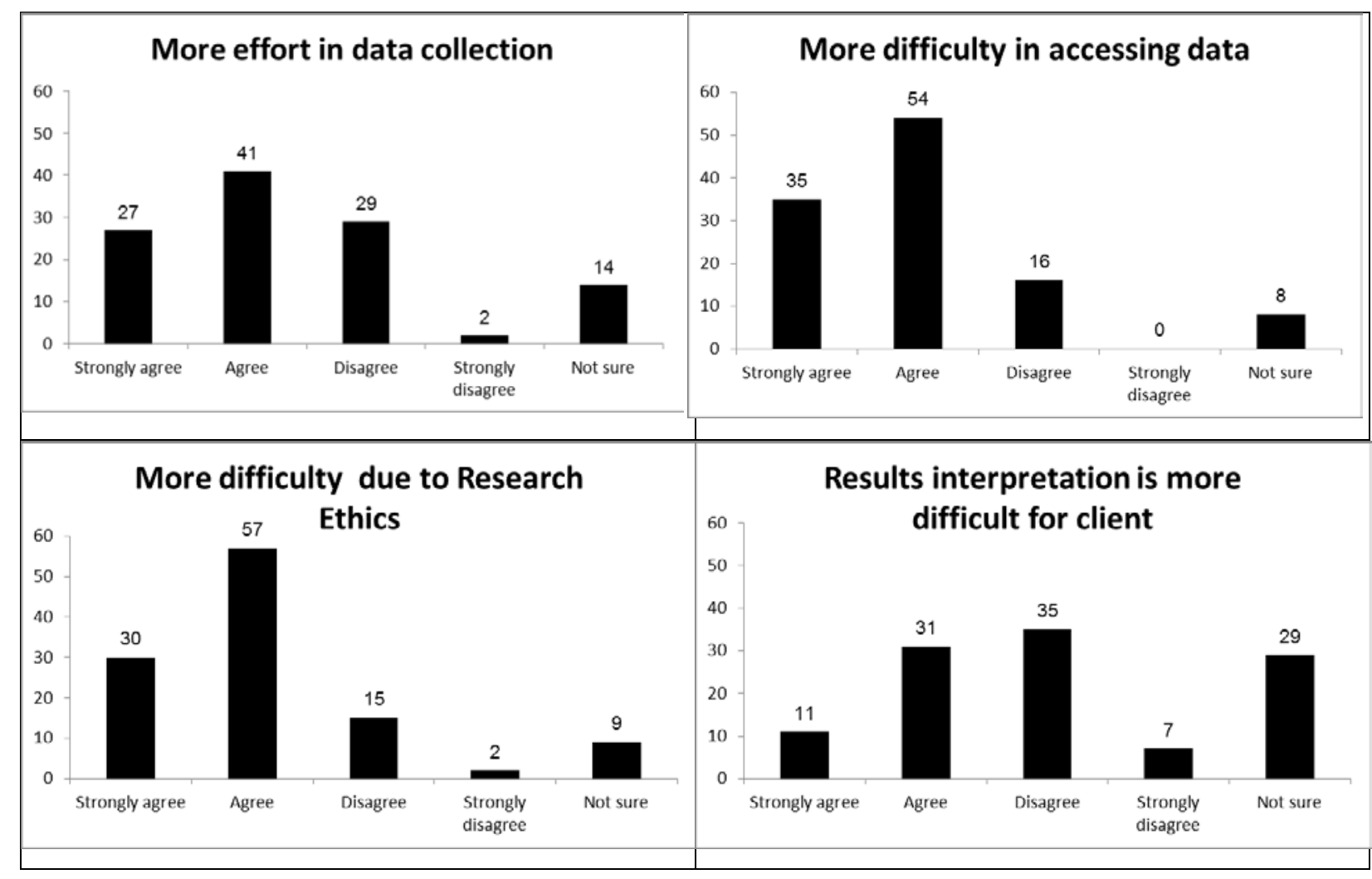

To confirm the above observations, the binomial test is used (Table 3) showing that at a $5 \%$ level there is a significantly higher proportion of agree and strongly agree responses that modelling in health is more difficult for the first three factors. However, opinions are equally divided on the difficulties encountered due to the client finding the interpretation of model results difficult.

Table 3 Proportion of grouped agree and disagree opinions on data issues and the results of the Binomial test comparing the two groups against the $H_{0}$ : there is no difference in the level of difficulty between modelling in health and in other sectors

\begin{tabular}{lcccc}
\hline \multicolumn{1}{c}{ Statement } & Agree & Disagree & $\begin{array}{c}\text { Binomial } \\
\text { test } \\
(p \text {-value })\end{array}$ & $\begin{array}{c}\text { Conclusion: Is health } \\
\text { modelling more } \\
\text { difficult? }\end{array}$ \\
\hline More effort in data collection & $69 \%$ & $31 \%$ & 0.000 & Yes (Reject $\left.\mathrm{H}_{0}\right)$ \\
$\begin{array}{l}\text { More difficulty in accessing data } \\
\begin{array}{l}\text { More difficulties due to research } \\
\text { ethics }\end{array}\end{array}$ & $85 \%$ & $15 \%$ & 0.000 & Yes (Reject $\left.\mathrm{H}_{0}\right)$ \\
$\begin{array}{l}\text { Client finds interpretation of results } \\
\text { more difficult }\end{array}$ & $54 \%$ & $16 \%$ & 0.000 & Yes (Reject $\left.\mathrm{H}_{0}\right)$ \\
\hline
\end{tabular}




\subsection{External Factors Perspective}

Three statements aimed to identify whether modelling in health is more difficult due to the effect of external factors: the influence of political events, the availability of simulation software and the rate at which results become obsolete. Figure 3 shows the frequency of respondents' opinions about each statement on the 4-point Likert scale and the 'not sure' option. The majority of the respondents seem to agree that these factors are more difficult to deal with in health than in other domains.

The binomial test (Table 4) shows that at a 5\% level there is a significant difference between the agree and disagree positions concerning the higher influence of political events. This implies that modelling in health is more difficult due to this factor. However no significant differences are found in the opinions about the rate at which results become obsolete or the availability of simulation software. 
Figure 3 Frequencies of respondents' opinions about the difference between modelling in health and other domains with respect to the effect of external factors

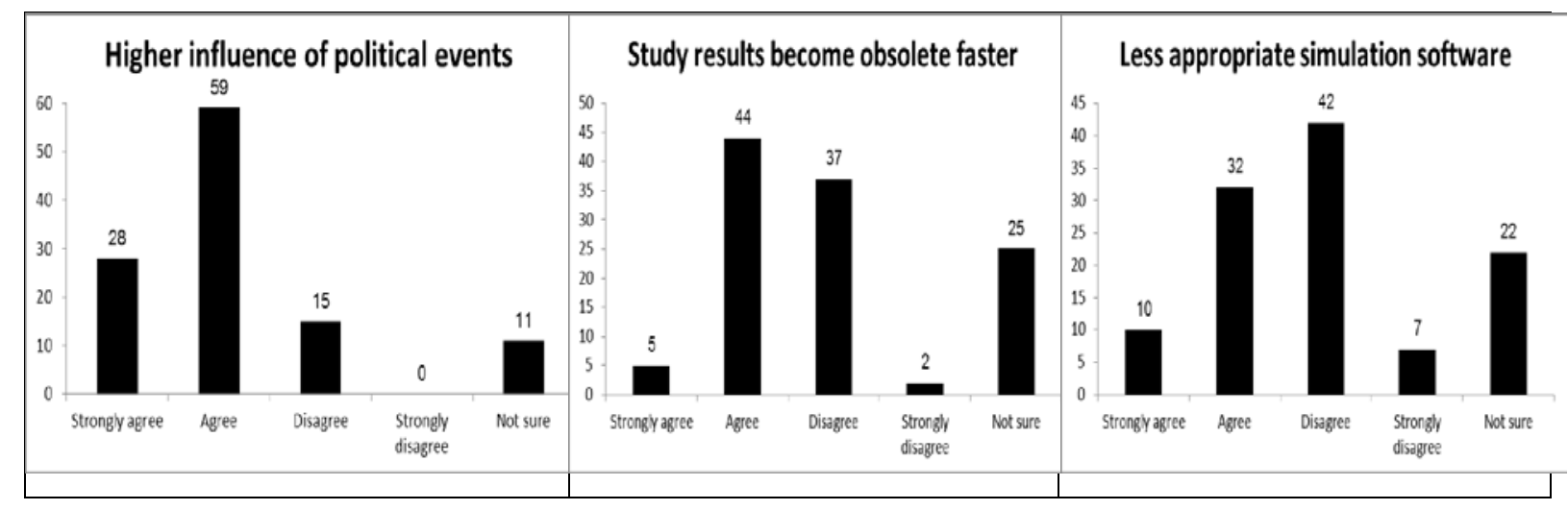

Table 4 Proportion of grouped agree and disagree opinions on effect of external factors and the results of the Binomial test comparing the two groups against the $H_{0}$ : there is no difference in the level of difficulty between modelling in health and in other sectors

\begin{tabular}{|c|c|c|c|c|}
\hline Statement & Agree & Disagree & $\begin{array}{c}\text { Binomial } \\
\text { test } \\
\text { (p-value) }\end{array}$ & $\begin{array}{c}\text { Conclusion: Is health } \\
\text { modelling more } \\
\text { difficult? }\end{array}$ \\
\hline $\begin{array}{l}\text { Higher influence of political } \\
\text { events }\end{array}$ & $85 \%$ & $15 \%$ & 0.000 & Yes (Reject $\mathrm{H}_{0}$ ) \\
\hline $\begin{array}{l}\text { Study results become obsolete } \\
\text { faster }\end{array}$ & $44 \%$ & $56 \%$ & 0.337 & No (Do not reject $\mathrm{H}_{0}$ ) \\
\hline $\begin{array}{l}\text { Less appropriate simulation } \\
\text { software }\end{array}$ & $46 \%$ & $54 \%$ & 0.530 & No (Do not reject $\left.\mathrm{H}_{0}\right)$ ) \\
\hline
\end{tabular}

\subsection{Organisational Factors Perspective}

Seven statements investigated perceptions about the organisational differences between simulation in health and other sectors. The bar charts in Figure 4 show the respondents' answers. A relatively higher number of agree responses are observed for the statements: less incentive to initiate change, more resistance to change, difficulty in developing generic models, more pronounced shortage of client time, and more difficulty in ensuring results are implemented. For the latter 2 statements, a relatively high number of 'not sure' answers can be also observed. An equal number of agree and disagree responses is observed for the statement that there is more resistance to accepting simulation results in health, where a relatively high number of 'not sure' responses is also present. However, there are relatively more disagree responses with respect to the statement that in health it is more difficult to identify relevant stakeholders. 
Figure 4 Frequencies of respondents' opinions about the difference between modelling in health and other domains with respect to organisational factors

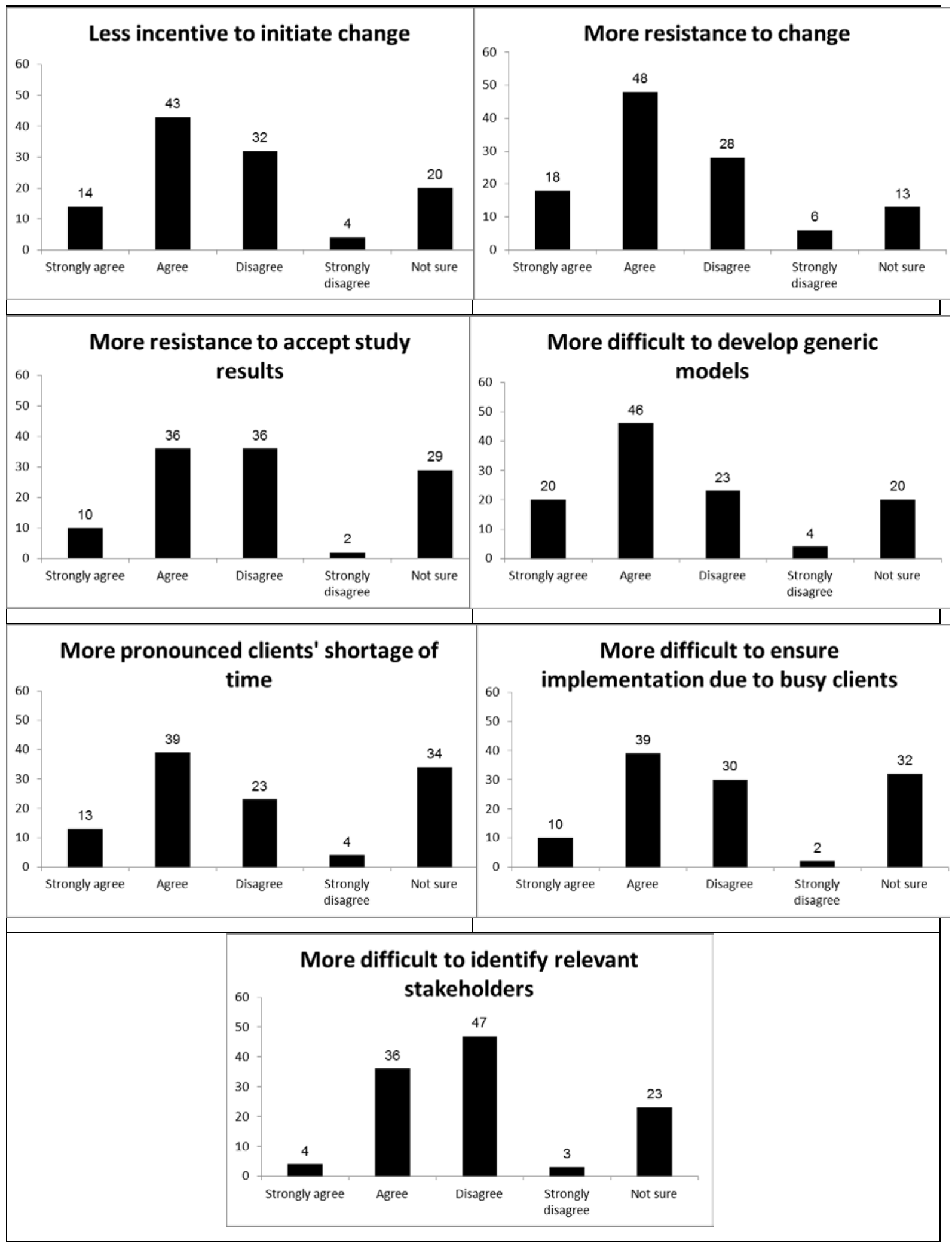


The binomial test (Table 5) confirms the observations above with the exception that there is no significant difference between the agree and disagree responses for the factor: more difficulty in ensuring results are implemented.

Table 5 Proportion of grouped agree and disagree opinions on effect of organisational factors and the results of the Binomial test comparing the two groups against the $\mathrm{H}_{0}$ : there is no difference in the level of difficulty between modelling in health and in other sectors

\begin{tabular}{lcccc}
\hline \multicolumn{1}{c}{ Statement } & Agree & Disagree & $\begin{array}{c}\text { Binomial } \\
\text { test } \\
(p \text {-value) }\end{array}$ & $\begin{array}{c}\text { Conclusion: Is health } \\
\text { modelling more difficult? }\end{array}$ \\
\hline $\begin{array}{l}\text { Less incentive to change } \\
\text { More resistance to change }\end{array}$ & $61 \%$ & $39 \%$ & 0.038 & Yes (Reject $\left.\mathrm{H}_{0}\right)$ \\
$\begin{array}{l}\text { Resistance to simulation results } \\
\text { More difficult to develop generic } \\
\text { models }\end{array}$ & $66 \%$ & $34 \%$ & 0.002 & Yes (Reject $\left.\mathrm{H}_{0}\right)$ \\
$\begin{array}{l}\text { Clients' shortage of time } \\
\text { More difficult to ensure } \\
\text { implementation }\end{array}$ & $71 \%$ & $29 \%$ & 0.000 & Yes (Reject $\left.\mathrm{H}_{0}\right)$ \\
$\begin{array}{l}\text { More difficult identifying } \\
\text { stakeholders }\end{array}$ & $66 \%$ & $34 \%$ & 0.007 & Yes (Reject $\left.\mathrm{H}_{0}\right)$ \\
\hline
\end{tabular}

\subsection{Overall Opinions: Health Modelling is Different to Other Sectors?}

The final question of the survey asked for respondents' opinions about whether modelling in health is different to other sectors. The responses are displayed in Figure 5, where the majority (64) of the respondents (57\%) agree and 11 (10\%) strongly agree with this statement. The binomial test comparing the proportions between the combined agree and disagree positions confirms that there is a significant difference in the answers to the two positions with $p$-value $=0.000$. 
Figure 5 Frequencies of respondents' opinions about the overall difference between modelling in health and other domains

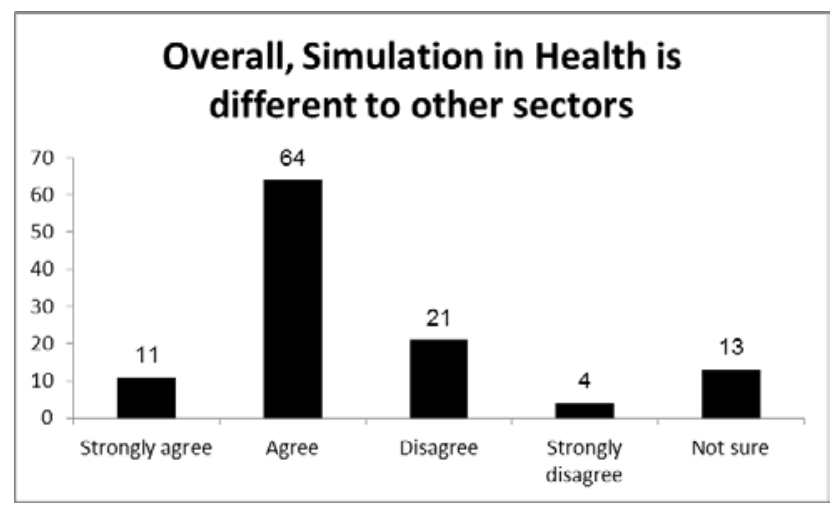

\section{SURVEY RESULTS: ANALYSIS BASED ON EXPERIENCE IN HEALTH MODELLING}

What we are not able to ascertain from the results in the previous section is whether there are differences in the responses of modellers that work in different sectors. Given the relative high percentage of simulation work performed in health by the respondents, this might suggest some bias in the results. We might expect that modellers tend to consider their own domain of application to be more complex than others because they know the detailed requirements for modelling in their own sector, but not in another's. This is something akin to the 'cognitive bias' identified by Kruger and Dunning (1999) where people hold inflated views of their competence in a social or intellectual domain. If such a bias exists, then there would be a tendency towards a perception of greater difficulty in health modelling due to the demographics of those that responded. To mitigate this, we now perform a more detailed analysis based on the individual respondent's experience of working in health.

First we inspect the data to identify evidence of cognitive bias. The data are split into three groups: those with no experience in health, those with less than $50 \%$ health experience and those with $50 \%$ or more health experience. The boundaries of these groups were selected on the basis of generating a reasonable sample size for each group. The sample sizes are 53, 32 and 28 respectively. The cumulative percentage of responses (strongly agree, agree, disagree and strongly disagree) for each group were calculated and a Kruskal-Wallis test (Kruskal and 
Wallis, 1952) performed to identify significant differences between the three distributions for each statement in the survey. The analysis focused only on respondents that expressed a clear opinion regarding a statement and so 'not sure' responses were excluded. Significant differences $(\alpha=0.05)$ between the cumulative distribution of responses were only found for three of the statements in the survey: more complex systems, problems are messier and the overall statement about whether simulation in health is different. Interestingly, the two individual statements that show a difference both come under the heading of the problem perspective.

Figure 6 shows the cumulative distributions for the three statements that elicited significant differences from the three groups. In all cases it is clear that a higher percentage of respondents with experience in health agree or strongly agree with the statements. Further, the group with most health experience, among whom ten have only worked in health, were most likely to agree or strongly agree with the statement. This difference in opinion between the respondent groups with different levels of health experience points to the potential for some level of cognitive bias for a subset of the statements in the survey. On the other hand, the differences could be the result of those with more experience in health modelling perceiving differences that do actually exist, but that modellers with little or no experience in health are not able to perceive. In order to mitigate these effects, the final part of the analysis focuses on the modellers with a balanced level of experience in both health and other sectors. For the purposes of this analysis, a balanced level of experience is defined as at least $25 \%$ of modelling work in health, but no more than $75 \%$. This gives a sample size of 25 respondents from the survey. We shall refer to these respondents as the 'balanced group'. 
Figure 6 Cumulative distribution of responses to questions for which there is a significant difference $(\alpha=0.05)$ between the distributions for different levels of health experience
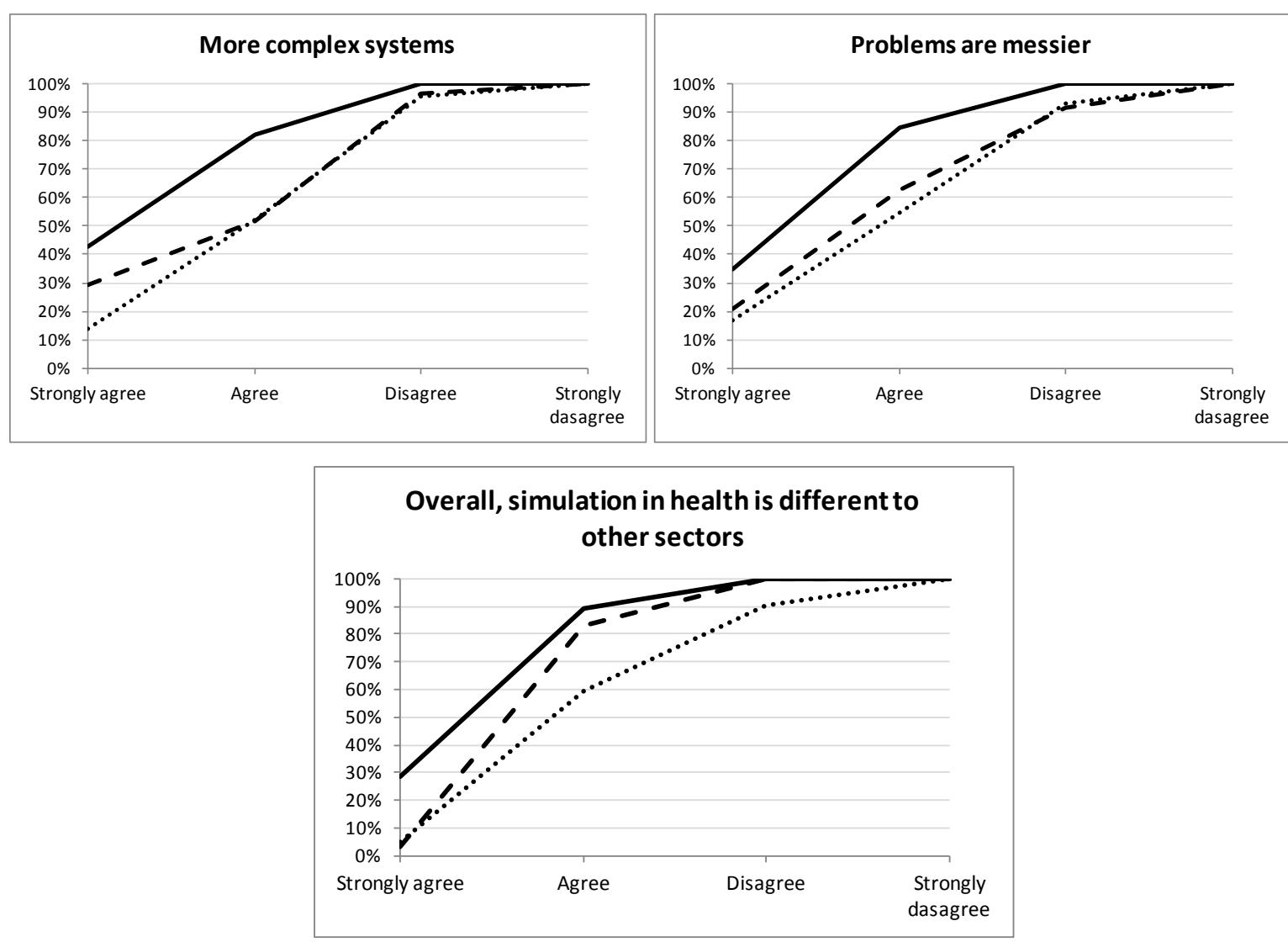

Key: \% experience in health

$$
\cdots \cdots=0 \%-\longrightarrow>0 \%,<50 \% \longrightarrow>=50 \%
$$

Table 6 presents the results for the balanced group for the statements on the nature of the problem; the second column gives the percentage that agree with each statement from the whole survey group (taken from table 2). The conclusions of the binomial test exactly match those for the whole survey group (table 2). It is notable, however, that for the three statements for which we conclude that health modelling is more difficult there is a higher percentage of respondents agreeing from the balanced group than from the whole survey group. This gives us greater confidence that there is less evident structure, more complex systems and messier problems in health. 
Table 6 Results for respondents with balanced experience in health and outside health: proportion of grouped agree and disagree opinions on the nature of problems

\begin{tabular}{lccccc}
\hline \multicolumn{1}{c}{ Statement } & $\begin{array}{c}\text { Whole } \\
\text { survey } \\
\text { agree }\end{array}$ & Agree & Disagree & $\begin{array}{c}\text { Binomial } \\
\text { test } \\
(p \text {-value) }\end{array}$ & $\begin{array}{c}\text { Conclusion: Is health } \\
\text { modelling more difficult? }\end{array}$ \\
\hline Less evident structure & $66 \%$ & $80 \%$ & $20 \%$ & 0.004 & Yes (Reject $\mathrm{H}_{0}$ ) \\
More complex systems & $60 \%$ & $76 \%$ & $24 \%$ & 0.015 & Yes (Reject $\mathrm{H}_{0}$ ) \\
Problems change more & $58 \%$ & $59 \%$ & $41 \%$ & 0.523 & No (Do not reject $\left.\mathrm{H}_{0}\right)$ \\
Problems are messier & $65 \%$ & $75 \%$ & $25 \%$ & 0.023 & Yes (Reject $\mathrm{H}_{0}$ ) \\
\hline
\end{tabular}

The results for the balanced group on data issues are shown in table 7. Again the binomial test results match those from the whole survey group (table 3). There is similarly a higher level of agreement with the statements from the balanced group with the exception of the difficulties concerning research ethics for which there is an equally high level of agreement at $84 \%$.

Table 7 Results for respondents with balanced experience in health and outside health: proportion of grouped agree and disagree opinions on data issues

\begin{tabular}{lccccc}
\hline & $\begin{array}{c}\text { Whole } \\
\text { Survey } \\
\text { Statement }\end{array}$ & $\begin{array}{c}\text { Bgree } \\
\text { agree }\end{array}$ & Disagree & $\begin{array}{c}\text { test } \\
(p \text {-value) }\end{array}$ & $\begin{array}{c}\text { Conclusion: Is health } \\
\text { modelling more difficult? }\end{array}$ \\
\hline $\begin{array}{c}\text { More effort in data } \\
\text { collection }\end{array}$ & $69 \%$ & $78 \%$ & $22 \%$ & 0.011 & Yes (Reject $\left.\mathrm{H}_{0}\right)$ \\
$\begin{array}{c}\text { More difficulty in accessing } \\
\text { data }\end{array}$ & $85 \%$ & $96 \%$ & $4 \%$ & 0.000 & Yes (Reject $\left.\mathrm{H}_{0}\right)$ \\
$\begin{array}{c}\text { More difficulties due to } \\
\text { research ethics }\end{array}$ & $84 \%$ & $84 \%$ & $16 \%$ & 0.001 & Yes (Reject $\left.\mathrm{H}_{0}\right)$ \\
$\begin{array}{c}\text { Client finds interpretation of } \\
\text { results more difficult }\end{array}$ & $50 \%$ & $57 \%$ & $43 \%$ & 0.664 & No (Do not reject $\left.\mathrm{H}_{0}\right)$ \\
\hline
\end{tabular}

Concerning external factors, there is no difference in the results between the whole survey group and the balanced group (table 8). Interestingly, the results concluded that both groups see no difference regarding the two statements that in health the study results become obsolete faster and the simulation software is less appropriate (table 4). These results confirm the findings from the whole survey group and suggest that the only external factor surveyed that increases the difficulty of health modelling is the influence of political events. 
Table 8 Results for respondents with balanced experience in health and outside health: proportion of grouped agree and disagree opinions on the effect of external factors

\begin{tabular}{lccccc}
\hline & $\begin{array}{c}\text { Whole } \\
\text { survey } \\
\text { agree }\end{array}$ & Agree & Disagree & $\begin{array}{c}\text { Binomial } \\
\text { test } \\
(p \text {-value) }\end{array}$ & $\begin{array}{c}\text { Conclusion: Is health } \\
\text { modelling more difficult? }\end{array}$ \\
\hline $\begin{array}{l}\text { Higher influence of political } \\
\text { events }\end{array}$ & $85 \%$ & $87 \%$ & $13 \%$ & 0.000 & Yes (Reject $\left.\mathrm{H}_{0}\right)$ \\
$\begin{array}{l}\text { Study results become } \\
\text { obsolete faster }\end{array}$ & $44 \%$ & $54 \%$ & $46 \%$ & 1.000 & No (Do not reject $\left.\mathrm{H}_{0}\right)$ \\
$\begin{array}{l}\text { Less appropriate simulation } \\
\text { software }\end{array}$ & $46 \%$ & $38 \%$ & $62 \%$ & 0.093 & No (Do not reject $\left.\mathrm{H}_{0}\right)$ \\
\hline
\end{tabular}

Table 9 presents the results on the organisational factors. Here we see a number of different conclusions based on the binomial test results from those for the whole survey group (table 5). Specifically, the balanced group do not identify a greater level of difficulty in health modelling for the statements concerning incentive to change, resistance to change and the difficulty of developing generic models; the whole survey group did signify a difference. Meanwhile, whilst the whole survey group did not consider that it is more difficult to ensure implementation in health, the balanced group did. The only two areas in which the balanced group identified that health modelling is more difficult is in the shortage of clients' time and in ensuring implementation. 
Table 9 Results for respondents with balanced experience in health and outside health: proportion of grouped agree and disagree opinions on the effect of organisational factors

\begin{tabular}{|c|c|c|c|c|c|}
\hline Statement & $\begin{array}{c}\text { Whole } \\
\text { survey } \\
\text { agree }\end{array}$ & Agree & Disagree & $\begin{array}{c}\text { Binomial } \\
\text { test } \\
\text { (p-value) }\end{array}$ & $\begin{array}{c}\text { Conclusion: Is health } \\
\text { modelling more difficult? }\end{array}$ \\
\hline Less incentive to change & $61 \%$ & $54 \%$ & $46 \%$ & 0.839 & No (Do not reject $\left.\mathrm{H}_{0}\right)^{*}$ \\
\hline More resistance to change & $66 \%$ & $63 \%$ & $38 \%$ & 0.307 & No (Do not reject $\mathrm{H}_{0}$ )* \\
\hline $\begin{array}{l}\text { Resistance to simulation } \\
\text { results }\end{array}$ & $55 \%$ & $42 \%$ & $58 \%$ & 0.648 & No (Do not reject $\left.\mathrm{H}_{0}\right) \dagger$ \\
\hline $\begin{array}{l}\text { More difficult to develop } \\
\text { generic models }\end{array}$ & $71 \%$ & $70 \%$ & $30 \%$ & 0.093 & No (Do not reject $\left.\mathrm{H}_{0}\right)^{*}$ \\
\hline Clients' shortage of time & $66 \%$ & $76 \%$ & $24 \%$ & 0.027 & Yes (Reject $\mathrm{H}_{0}$ ) \\
\hline $\begin{array}{l}\text { More difficult to ensure } \\
\text { implementation }\end{array}$ & $60 \%$ & $77 \%$ & $23 \%$ & 0.017 & Yes (Reject $\left.\mathrm{H}_{0}\right)^{*}$ \\
\hline $\begin{array}{l}\text { More difficult identifying } \\
\text { stakeholders }\end{array}$ & $44 \%$ & $55 \%$ & $45 \%$ & 0.824 & No (Do not reject $\mathrm{H}_{0}$ ) \\
\hline
\end{tabular}

* Binomial test result different from whole survey result

† Sample size $n=19$ (6 not sure responses), hence requirement for $p n \geq 10$ for binomial test not met $(p$-value=0.5)

A higher proportion (84\%) of the balanced group agree or strongly agree that simulation in health is different, with only $67 \%$ in these categories for the whole survey group. The binomial test shows a significant difference between the combined agree and disagree positions $(p$-value $=0.001)$. The responses are summarised in figure 7 .

Figure 7 Frequencies of respondents' opinions from the balanced group about the overall difference between modelling in health and other domains

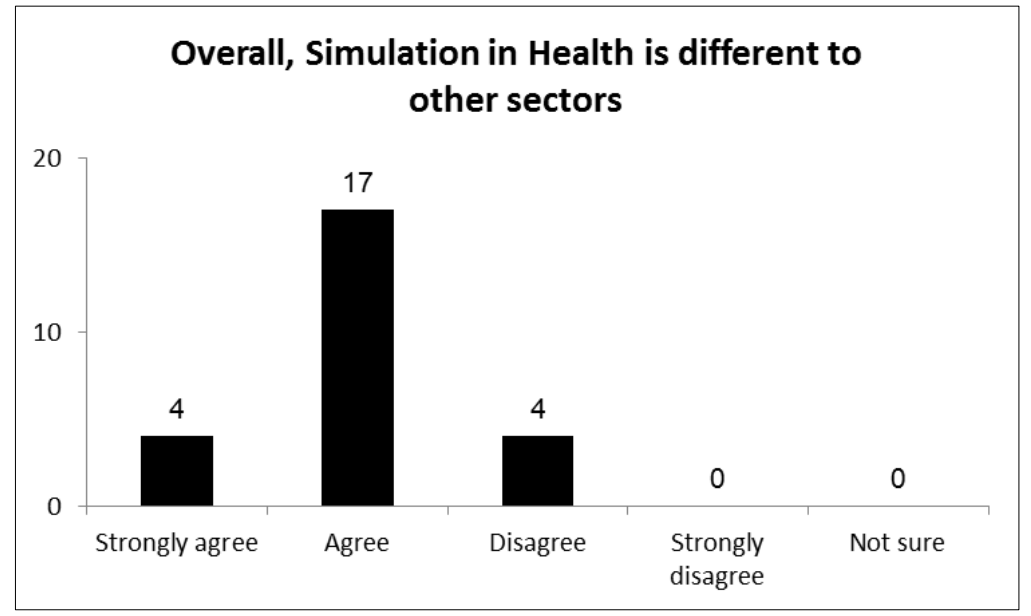




\section{SURVEY RESULTS: COUNTRY ANALYSIS}

One specific question is whether the nature of the health service in a country impacts on the issues involved in performing health simulation work. In particular, whether there is a difference between work in a predominantly public health service against a private health system. We might expect greater similarity between work in a private health system and work in other, predominantly privately owned, sectors.

Given that a high proportion of the respondents were from the United Kingdom (predominantly public health system) and the USA (predominantly private health system), an analysis of these differences is possible. Against our expectations, figure 8 appears to show that respondents from the USA perceive a greater difference in health modelling. However, this figure must be interpreted with caution due to the sample sizes involved; there were only ten respondents from the UK while there were 66 from the USA. Indeed, a Mann-Whitney U test shows no significant difference between these distributions.

Due to the sample size from the UK, no firm conclusion can be reached from these data. Also, it was not deemed worthwhile performing a more detailed analysis of the individual factors. 
Figure 8 Cumulative distribution of responses to question about overall difference between modelling in health and other domains; comparing responses from UK and USA

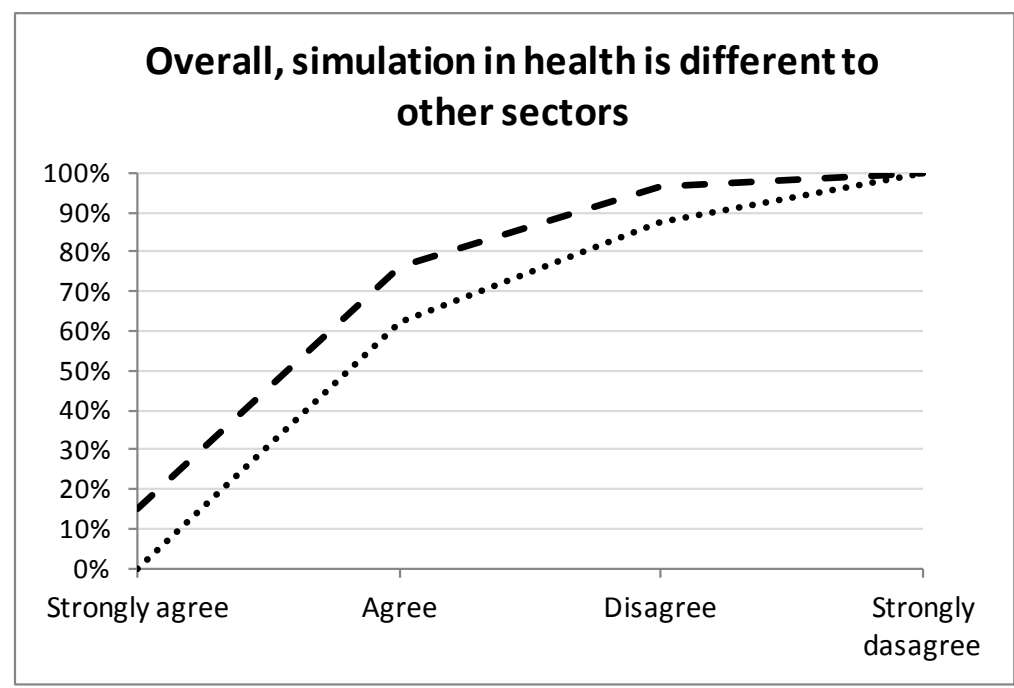

Kev: Countrv

$$
\cdots \cdot \cdot=\text { UK } \quad-\quad-=\text { USA }
$$

\section{DISCUSSION AND CONCLUSION}

The results show that for many factors a significant majority of respondents perceive that health modelling is more difficult than in other sectors. In summary, according to the respondents with between $25 \%$ and $75 \%$ health modelling experience, in health simulation there is:

- Less evident structure

- More complex systems

- Messier problems

- More effort required for data collection

- More difficulty in accessing data

- More difficulties due to research ethics

- Greater influence from political events

- Less client time available

- More difficulty in ensuring implementation 
The overall survey group did not agree that there was more difficulty in ensuring implementation in health. The overall group also stated that in health simulation there is:

- Less incentive to initiate change

- More resistance to change

- Greater difficulties in developing generic models

However, the group with experience in both health and other sectors did not agree.

Overall, there is a perception that health modelling is different. Some of the respondents that supported a difference provided additional comments at the end of the survey. These comments refer to the involvement of human factors in the service, both from the side of the provider (clinical staff) and receiver (patients), the fragmented nature of the services, lack of data and the politically charged environment. These seem to be in their opinion the main source of the perceived differences.

Of course, we must discuss the validity of these results. We have already recognised that the survey measured the respondents' perceptions and as such it is not based on objective evidence. What the survey shows is that many of the respondents agreed with the literature statements about the difficulties of health modelling. It would be useful now to try and identify objective evidence to corroborate these perceptions. For instance, could we measure the time spent collecting and analysing data in typical simulation studies in health and other sectors? Can we measure the complexity of the systems and models generated in different sectors? Could we determine the availability of clients in different sectors? These are not necessarily easy to measure, but it might be possible to identify and measure indicators for each factor.

Although a significant majority perceived greater difficulty in health modelling for most of the factors, there are many respondents that do not agree. What we do not know is whether they believe there is no difference for those factors, or whether they believe that modelling in the other sectors is more difficult. Some of the respondents' comments provide further insights about their views. For example, one of the respondents with experience both in health and manufacturing commented that the problems faced are similar, with the difference 
being mainly the modelling of decisions made by medical staff. Others, with experience in areas other than health, such as manufacturing or construction, suggest that modelling in their respective domain areas is more complex or less well defined compared to health. It would be interesting to investigate this in more detail.

Assuming that we accept the results of this survey, then the findings have implications for simulation research and practice. From a research perspective we need to seek ways to mitigate these factors by advancing knowledge in simulation modelling in health. For instance, how can simulation be made more amenable to messier problems or situations where good data are not available? Solutions may lie in technological improvements such as simulation software developments and improved methods for managing data. They may also lie in innovative ways of managing simulation projects especially in the face of limited data, messy problems and lack of client time. From a practitioners perspective, the differences in health modelling similarly require adaptation of the standard approaches for developing and using simulation models. New approaches based around workshops supported by problem structuring methods (Kotiadis et al, 2013) or facilitated modelling (Robinson et al, 2014) could prove beneficial. These require quite different skills to the traditional simulation modeller, with a focus more on softer skills such as communication, facilitation, and leading healthcare clients to identification of improvements.

For now, our results show that it is perceived that there are significant differences in health modelling and that health modelling is more difficult across a range of factors. Further investigation is required to determine whether these results continue to hold when more objective measures are applied. It would also be interesting to investigate whether the nature of the health system, public or private, has an impact on the issues involved in performing health simulation work.

\section{ACKNOWLEDGEMENTS}

We would like to thank Lakshman Aram (MSc student from Warwick Business School) for his help in the construction of the questionnaire. 
This paper is adapted and extended from: Tako, A.A. and Robinson, S. (2012). Is Simulation in Health Different and is it More Difficult? Proceedings of the $6^{\text {th }}$ Simulation Workshop (SW12) (B.Tjahjono, C. Heavey, S. Onggo, eds.), Operational Research Society, Birmingham, pp. 92-101.

\section{REFERENCES}

Brailsford SC (2005). Overcoming the Barriers to Implementation of Operations Research Simulation Models in Healthcare. Clinical and Investigative Medicine, 28, pp. 312-315.

Brailsford SC, Bolt T, Connell C, Klein JH and Patel B (2009). Stakeholder Engagement in Health Care Simulation. In: Rossetti MD, Hill RR, Johansson B, Dunkin A and Ingalls RG (eds.). Proceedings of the 2009 Winter Simulation Conference. IEEE: Piscataway, NJ, pp. 1840-1849.

Brailsford SC, Bolt TB, Bucci G, Chaussalet TM, Connell NA, Harper PR, Klein JH, Pitt M and Taylor M (2013). Overcoming the Barriers: A Qualitative Study of Simulation Adoption in the NHS (2013). Journal of the Operational Research Society, 64 (2), pp. 157-168.

Eldabi T (2009). Implementation Issues of Modeling and Healthcare Problems: Misconceptions and Lessons. In: Rossetti MD, Hill RR, Johansson B, Dunkin A and Ingalls RG (eds.). Proceedings of the 2009 Winter Simulation Conference. IEEE: Piscataway, NJ, pp. 1831-1839.

Fackler J and Spaeder M (2011). Why Doesn’t Healthcare Embrace Simulation and Modeling? What Would it Take? In: Jain, S, Creasey RR, Himmelspach J, White KP and Fu M (eds.). Proceedings of the 2011 Winter Simulation Conference. IEEE: Piscataway, NJ, pp. 1137-1142.

Fone D, Hollinghurst S, Temple M, Round A, Lester N, Weightman A, Roberts K, Coyle E, Bevan G and Palmer S (2003). Systematic Review of the Use and Value of Computer Simulation Modelling in Population Health and Health Care Delivery. Journal of Public Health Medicine, 25 (4), pp. 325-335. 
Günal MM and Pidd M (2010). Discrete Event Simulation for Performance Modelling in Health Care: A Review of the Literature, Journal of Simulation, 4 (1), pp. 42-51.

Harper PR and Pitt MA (2004). On the Challenges of Healthcare Modelling and a Proposed Project Life-Cycle for Successful Implementation. Journal of the Operational Research Society 55: 657-661.

Harper PR and Shahani AK (2002). Modelling for the Planning and Management of Bed Capacities in Hospitals. Journal of the Operational Research Society, 53, pp. 11-18.

Jacobson SH, Hall SN and Swisher JR (2006). Discrete-Event Simulation of Health Care System. Patient Flow: Reducing Delay in Healthcare Delivery (R.W. Hall, ed.), Springer International Series, pp. 211-252.

Jahangirian M, Naseer A, Stergioulas L, Young T, Eldabi T, Brailsford S, Patel B and Harper P (2012). Simulation in Health-Care: Lessons from Other Sectors, Operational Research: An International Journal, 12 (1), pp. 45-55.

Jun JB, Jacobson SH and Swisher JR (1999). Application of Discrete-Event Simulation in Health Care Clinics: A Survey. Journal of the Operational Research Society, 50 (2), pp. 109123.

Kirchhof P and Meseth N (2012). A Survey of the Use of Simulation in German Healthcare. In: Laroque C, Himmelspach J, Pasupathy R, Rose $\mathrm{O}$ and Uhrmacher AM (eds.). Proceedings of the 2012 Winter Simulation Conference. IEEE: Piscataway, NJ

Kotiadis K, Tako AA and Vasilakis C (2013). A Participative and Facilitative Conceptual Modelling Framework for Discrete Event Simulation Studies in Healthcare. Journal of the Operational Research Society, forthcoming.

Kruger J and Dunning D (1999). Unskilled and Unaware of It: How Difficulties in Recognizing One's Own Incompetence Lead to Inflated Self-Assessments. Journal of Personality and Social Psychology, 77 (6), pp. 1121-1134. 
Kruskal W and Wallis WA (1952). Use of Ranks in One-Criterion Variance Analysis. Journal of the American Statistical Association, 47 (260), pp. 583-621.

Kuljis J, Paul RJ and Stergioulas LK (2007). Can Health Care Benefit from Modeling and Simulation Methods in the Same Way as Business and Manufacturing Has? In: Henderson SG, Biller G, Hsieh M-H, Shortle J, Tew JD and Barton RR (eds.). Proceedings of the 2007 Winter Simulation Conference. IEEE: Piscataway, NJ, pp. 1449-1453.

Lane DC, Monefeldt C and Husemann E (2003). Client Involvement in Simulation Model Building: Hints and Insights from a Case Study in a London Hospital. Health Care Management Science, 6 (2), pp. 105-116.

Lowery JC, Hakes B, Lilegdon WR, Keller L, Mabrouk K and McGuire F (1994). Barriers to Implementing Simulation in Health Care. In: Tew JD, Manivannan S, Sadowski DA and Seila AF (eds.). Proceedings of the 1994 Winter Simulation Conference. IEEE: Piscataway, NJ, pp. 868-875.

Mustafee N, Katsaliaki K and Taylor SJE (2010). Profiling Literature in Healthcare Simulation. Simulation, 86 (8-9), pp. 543-558.

Naseer A, Eldabi T and Jahangirian M (2009). Cross-Sector Analysis of Simulation Methods: A Survey of Defense and Healthcare, Transforming Government: People, Process and Policy, 3 (2), pp. 181-189.

Pitt M (2008). Simulation for Strategic Planning in Health Care - 'The State of the Art.' Briefing Report for the Institute: www.institute.nhs.uk/images//documents/BuildingCapability/ScenarioGenerat or/state-of-the-art.pdf (Accessed Jme 2013February 2014).

Robinson S, Brooks RJ, Kotiadis K and van der Zee D-J (2010). Conceptual Modelling for Discrete-Event Simulation. Chapman and Hall/CRC Boca Raton: FL, USA. 
Robinson S, Worthington C, Burgess N and Radnor ZJ (2014). Facilitated Modelling with Discrete-Event Simulation: Reality or Myth? European Journal of Operational Research, forthcoming.

Sheskin DJ (2007). Handbook of Parametric and Nonparametric Statistical Procedures, fourth ed. Chapman and Hall/CRC, Boca Raton: FL, USA.

Sobolev B, Sanchez V and Vasilakis C (2011). Systematic Review of the Use of Computer Simulation Modeling of Patient Flow in Surgical Care, Journal of Medical Systems, 35, pp. 116.

Tunnicliffe Wilson JC (1981). Implementation of Computer Simulation Projects in Health Care. Journal of the Operational Research Society, 32 (9), pp. 825-832.

van Lent WA, VanBerkel P, van Harten WH (2012). A Review on the Relation between Simulation and Improvement in Hospitals. BMC Medical Informatics and Decision Making, $12(18)$.

Young T, Eatock J, Jahangirian M, Naseer A and Lilford R (2009). Three Critical Challenges for Modelling and Simulation in Healthcare. In: Rossetti MD, Hill RR, Johansson B, Dunkin A and Ingalls RG (eds.). Proceedings of the 2009 Winter Simulation Conference. IEEE: Piscataway, NJ, pp. 1823-1830. 